\title{
ANALYSIS OF PLASTIC DEFORMATION OF DOUBLE REDUCED SHEETS
}

\author{
Emil SPIŠÁK*, Janka MAJERNÍKOVÁ*, Emília DUL'OVÁ SPIŠÁKOVÁ*, L'uboš KAŠČÁK* \\ *Faculty of Mechanical Engineering, Department of Technologies and Materials, Technical University of Košice, \\ Letná 9, 04001 Košice, Slovakia \\ "University of Economics in Bratislava, Faculty of Business Economy with seat in Košice, Tajovského 13, Slovakia \\ emil.spisak@tuke.sk, jana.majernikova@tuke.sk, emilia.spisakova@euke.sk, lubos.kascak@tuke.sk
}

received 12 November 2015, revised 23 November 2016, accepted 28 November 2016

\begin{abstract}
This paper discusses the causes and the effects of plastic deformation of double reduced sheets under uniaxial and biaxial loading. It focuses on the specific inhomogeneity and localization of plastic deformation, which is analysed in detail. The uniaxial and the hydraulic biaxial tensile tests were used for material testing and the results were compared and evaluated. The final part of the paper deals with the microstructure of material deformations.
\end{abstract}

Key words: Tinplates, Double Reduction, Tensile Tests, Plastic Deformation

\section{INTRODUCTION}

An accurate determination of mechanical properties is one of the key issues in the analysis of behaviour of material deformation. Tinplate forming is characterized by a phenomenon of specific inhomogeneity, of which causes and effects are analysed in this paper. Tinplates can be classified according to the type of production, into the simply reduced (SR) and the double reduced (DR) sheets. The thickness of the sheets is effected by the method of production, and it ranges from 0.13 to $0.50 \mathrm{~mm}$. A significant strain hardening of the material occurs during the process of production, with the use of a cold rolling tandem mill. This adverse effect is eliminated either by a continuous annealing (CA) or by a batch annealing (BA). Protection tin coating is applied on the modified material, it brings several advantages such as excellent formability, sufficient strength and corrosion resistance (European Standard 2001). Modern tinplate has several important advantages, including excellent drawability combined with good strength, good solderability and corrosion resistance.

DR tinplate is currently and mostly tested by the tension test (uniaxial tensile test). However, this test showed that there is severe variance in the case of identified mechanical and plastic properties. Significantly high variance is observed in the case of material plasticity which is demonstrated through the material elongation. The measured properties of DR tinplate after the elongation, which were identified by the uniaxial tensile test, tend to be very low (starting at $0.2 \%$ ). We tried to experimentally test the behaviour of DR tinplate by means of a hydraulic biaxial tensile test which uses hydrostatic bulging and to analyse the root causes of non-homogenous plastic deformation with subsequent disruption of tested specimens during tension test (Spišák et al., 2012).

\section{LOCAL PLASTIC DEFORMATION AND ITS PROGRESS}

Plastic deformation of material can be generally divided into and dealt with at the three levels, namely micro, meso and macro level. In a majority of low-carbon sheets, deformation takes place evenly along the whole length of the test specimen, until a certain phase of the process where the loss of stability occurs, which is manifested through the local narrowing and thinning of the specimen (Fig. 1). a)

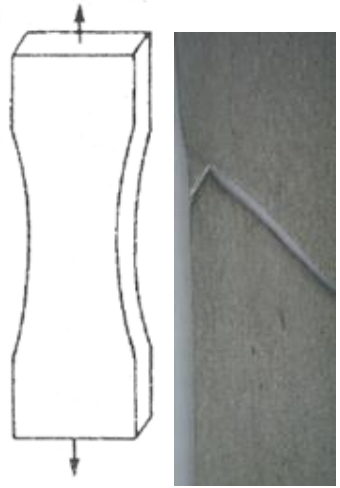

b)

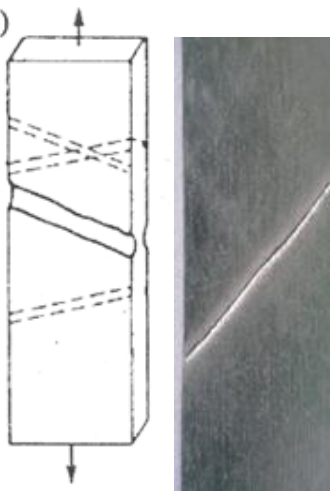

c)

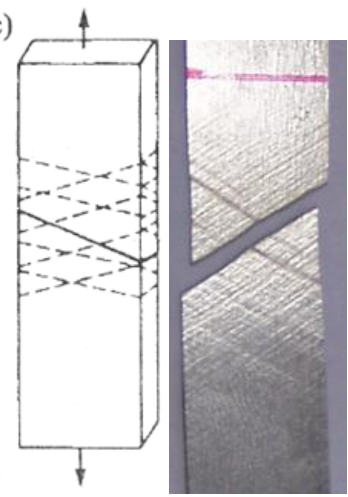

Fig. 1. Ways of loss of stability of the test specimen: a) without localization of deformation, b) Marciniak model, c) several slip lines (European Standard EN 10202:2001, 2001) 
The reduction of width and thickness of the material continues until another type of the stability loss in the area appears. The loss of stability of the plate appears as a local change, there is a change of its thickness along the certain line. This type of deformation can be observed as a local thinning visible on the surface of the specimen (Fig. 1b). Its width depends on the thickness of the sheet. The local thinning continues until the slip strips appear across its whole length. When the loss of stability of the material occurs, local deformation appears in the form of shear bands (Fig. 1c) at the moment when the load reaches the maximum. Methods for localization of deformation as well as the conditions of the loss of stability were described by many authors (Hill, 1952; Marciniak, 1978; Swift, 1952).

Generally, there are three basic models of the loss of stability, which are accepted (Fig. 1), including a model of the diffusion thinning (Swift, 1952), the localized thinning (Hill, 1952) and a model of the initial inhomogeneity in the material - Fig. 1b (Marciniak, 1978).

Deformation proceeds at a decreased stress level, known as the lower yield stress, but it is inhomogeneous. The specimen is divided into the regions where the strain is relatively high (Lüders strain) and the regions which are still elastic. The distinct plateau in the stress-strain curve is characterized by the propagation of Lüders bands. The propagation of Lüders bands is influenced by many factors including crystal structure, grain size, composition and microstructure, shape and stiffness of the testing specimen, strain rate and the type of loading. Experimental study of local deformation has been described previously by the authors (Zhang and Jiang, 2004). It was found out that the strain at the beginning of Lüders band is lower than the total strain. Generally, this phenomenon is important in the process of material deformation (Zhang and Jiang, 2004a, b).

\section{MATERIAL FOR THE EXPERIMENTAL RESEARCH}

Tinplate TH 415 CA with the thickness of $0.18 \mathrm{~mm}$ was used for the experiment. The tinplate had been processed by double reduction and continuous annealing. The specimens were taken in the rolling direction $\left(0^{\circ}\right)$ and the direction perpendicular to the rolling direction $\left(90^{\circ}\right)$. The chemical composition of the material is given in Tab. 1 .

Tab. 1. Chemical composition of the material TH 415 CA expressed in [wt. \%]

\begin{tabular}{cccccccc}
\hline $\mathrm{Fe}$ & $\mathbf{C}$ & $\mathrm{Si}$ & $\mathrm{Mn}$ & $\mathbf{P}$ & $\mathrm{S}$ & $\mathrm{Cu}$ & $\mathrm{Al}$ \\
99.52 & 0.075 & 0.022 & 0.130 & 0.014 & $<0.002$ & 0.030 & 0.065 \\
$\mathrm{Cr}$ & $\mathrm{Mo}$ & $\mathbf{N i}$ & $\mathbf{V}$ & $\mathrm{Ti}$ & $\mathrm{Nb}$ & $\mathrm{Co}$ & $\mathbf{W}$ \\
0.009 & 0.013 & 0.005 & 0.009 & $<0.002$ & 0.018 & 0.036 & 0.048 \\
\hline
\end{tabular}

In order to identify the mechanical properties of the tested material, uniaxial tensile test (Fig. 2a) and hydraulic biaxial tensile test (Fig. 2b - Bulge test) were conducted. The plastic deformation is observed in particular areas on the specimens. The specimens were difficult to evaluate because numerous damages occurred out of the measured section of specimens. Besides the deformation in the observed area, there occurred damage in other locations, with cracks of different shapes; however, major part of the specimen remained without plastic deformation, as illustrated in Fig. 3. Mechanical properties of the tested material TH $415 \mathrm{CA}$ obtained from uniaxial tensile test are shown in the Tab. 2.

a)

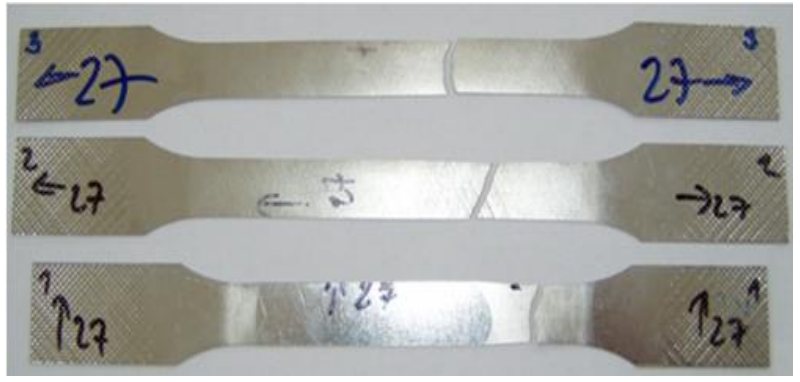

b)

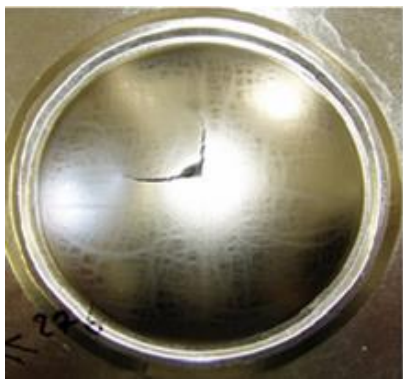

Fig. 2. Specimen No. 27: a) uniaxial tensile test,

b) hydraulic biaxial tensile test

a)

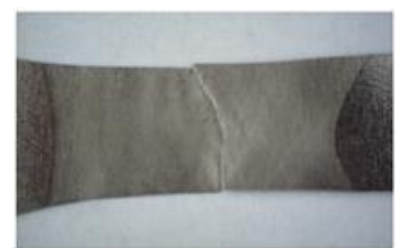

c)

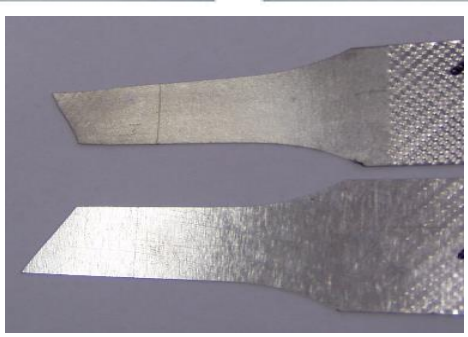

Fig. 3. Detail of plastic undeformed parts of specimen after uniaxial tension test: a) local deformation with a fracture, b) local deformation without a fracture, $c$ ) fractured material after plastic deformation and without plastic deformation

Tab. 2. Mechanical properties of material obtained from uniaxial tensile test

\begin{tabular}{cccc}
\hline $\begin{array}{c}\text { Specimen } \\
\text { number }\end{array}$ & $\mathrm{R}_{\mathrm{p} 0,2}[\mathrm{MPa}]$ & $\mathrm{R}_{\mathrm{m}}[\mathrm{MPa}]$ & $\mathrm{A}_{50}[\%]$ \\
\hline$\div \mathbf{2 7 0 ^ { \circ }}$ & $\mathbf{4 5 0 . 7}$ & $\mathbf{4 4 3}$ & $\mathbf{2 1 . 6 1}$ \\
$\div \mathbf{2 7} \mathbf{9 0}$ & $\mathbf{5 0 4}$ & 499.7 & 1.89 \\
\hline
\end{tabular}

The specimen obtained from hydraulic biaxial test after failure is documented in Fig. 2b. Slip bands were clearly visible in the deformed area of specimens. Anisotropic properties obtained from this test are shown in Tab. 3.

Tab. 3. Mechanical properties of tested steel sheet obtained from hydraulic biaxial tensile test

\begin{tabular}{ccccc}
\hline $\begin{array}{c}\text { Specimen } \\
\text { number }\end{array}$ & $\mathrm{R}_{\mathrm{p} 0,2}[\mathrm{MPa}]$ & $\mathrm{R}_{\mathrm{m}}[\mathrm{MPa}]$ & $\mathrm{A}[\%]$ & $\mathrm{h}_{\text {dome }}[\mathrm{mm}]$ \\
\hline$\div 27$ & $\mathbf{3 7 0}$ & $\mathbf{5 0 7 . 3}$ & $\mathbf{1 2 . 5 9}$ & 17.7 \\
\hline
\end{tabular}




\section{EXPERIMENTAL METHODS}

Uniaxial tensile test was carried out on the TIRA test 2300. Test conditions and the shape of the specimen corresponded to standards STN EN 10002-1+AC1 and STN 420321.

Hydraulic biaxial tensile test was performed on the equipment for hydraulic bulging (Bulge test). The test plate is clamped between the bottom plate and die with a diameter of $80 \mathrm{~mm}$. The blankholder prevents pulling material through the rib located in die. Fluid pressure is used for deformation and subsequent burst of the specimen. The plastic properties of the tested plate are identified from the height of the bulge and shape of the crack after the bulge is damaged. Hydraulic biaxial tensile tests are used for evaluation of parameters such as yield strength $R_{e}$, ultimate tensile strength $R_{m}$, total elongation of specimen $A_{50}$ and the height of bulge $h$. Hydraulic bulge test was performed using six specimens of steel sheet TH 415CA with thickness $0.18 \mathrm{~mm}$ and size $130 \mathrm{~mm} \times 130 \mathrm{~mm}$.

Subsequently, metallographic observation of material structure was performed. Specimens were observed and evaluated using a GX 71 Olympus light microscope. Specimens were taken from deformed parts after uniaxial (Fig. 4) and hydraulic biaxial tensile tests (Fig. 5). Figs. 4 and 5 show areas marked with highlighted detail " $C$ " for metallographic observation, which is shown in Figs. 6 and 7.

a)

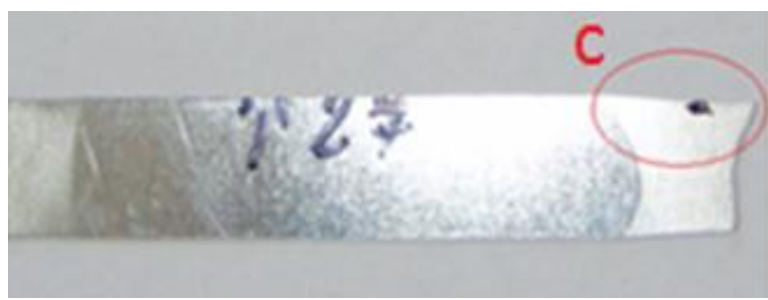

b)

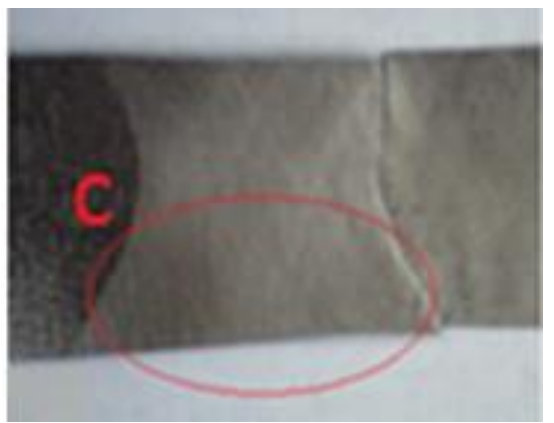

Fig. 4. Specimen for metallographic observation: a) detail "C", b) after uniaxial tensile test

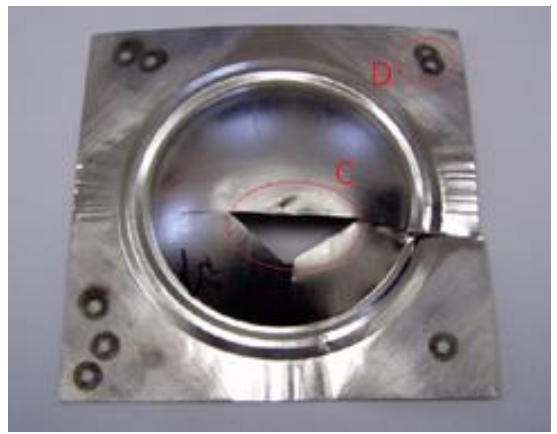

Fig. 5. Specimen for metallographic observation - detail "C" and for the analysis of the chemical composition of the material - detail " $D$ " (hydraulic biaxial tensile test)

\section{EXPERIMENTAL RESULTS AND THEIR ANALYSIS}

Tinplate TH 415 CA was used for metallographic observation of the microstructure. After uniaxial tensile test in the $0^{\circ}$ direction, the microstructure showed significantly elongated grains in the rolling direction, which is the result of the double reduction (Fig. 6a). The microstructure of the specimen taken in the $90^{\circ}$ direction is characterized by uniform structure (Fig. 6b). The localization of deformation and fracture of specimens in the tensile test can be explained by Marciniak's theory, according to which the localization of deformation occurs in areas with a strong inhomogeneity of the material. Inhomogeneity of the material can cause changes in the surface micro-geometry; internal inhomogeneity of the material can cause a lot of surface defects. The depth of defects plays the main role in this process. Non-metallic inclusions - oxides were observed at these locations and at the coupling of the base material with deformation slivers. Their presence depends on the material conditions of annealing (Fig. 6a, b).

a)

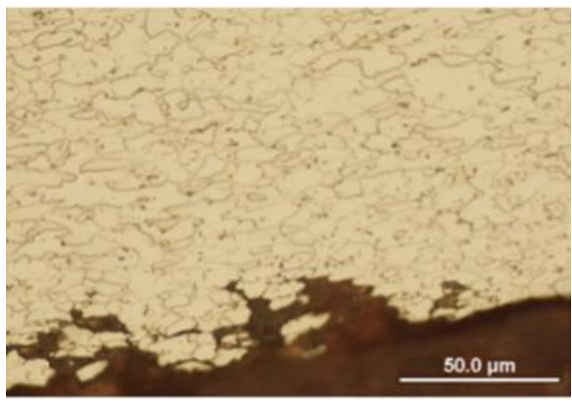

b)

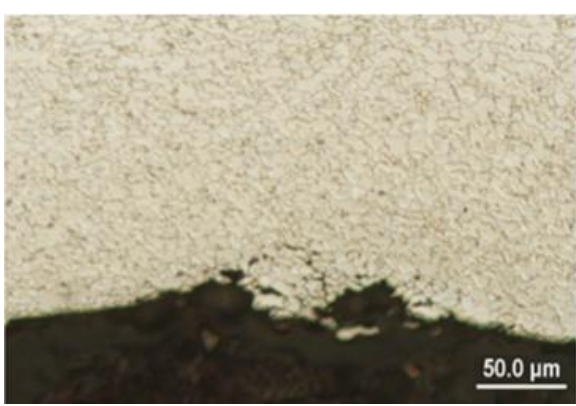

Fig. 6. Deformed material structure after uniaxial tensile test taken from place "C": a) rolling direction $0^{\circ}$, b) rolling direction $90^{\circ}$

The average value of elongation of tinplate in the $0^{\circ}$ direction was $2 \%$, and it reached $22 \%$ in the $90^{\circ}$ direction. Significant difference was observed in the mechanical properties of specimen taken in the $0^{\circ}$ and $90^{\circ}$ direction, particularly in their nondeformed parts. The value of elongation difference observed in most cases was up to $100 \%$.

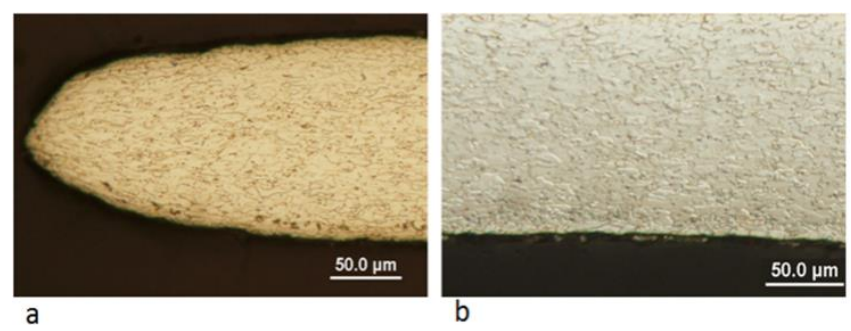

Fig. 7. Deformed material structure after hydraulic biaxial tensile test test taken from place "C" in rolling direction $0^{\circ}:$ a) area of fracture, b) base material 
To determine the properties of tinplate, hydraulic biaxial tensile test appeared to be preferable. The average value of elongation of this material was $13 \%$. The microstructure of the deformed material was also characterized by a uniform structure in the failure area, which was typically plastic with a significant narrowing (Fig. 7a, b). Breakage of the specimen is initiated at a particular location when the slip bands and thinning occur. They are not able to resist the increasing tension, which results in the failure of material.

\section{CONCLUSIONS}

Firstly, this paper described the causes and consequences of the loss of stability and violations of tinplate in uniaxial and biaxial tensile loading. Secondly, it analysed the deformation and loss of stability in individual tests. The metallographic structure of material was observed, which served for the analysis of the structure and mechanism of plastic deformation. At the very beginning of plastic deformation in the uniaxial tensile test, the slip lines are generated; these exist in areas with inner inclusions in material. In these spots, as tension force increases, deformation is localized in the area of slip plains without spreading plastic deformation along the whole length of test specimen. The test specimen disrupts in this spot.

In case of hydraulic biaxial tensile test, the difference between yield strength $\mathrm{Rp} 0.2$ and $\mathrm{Rm}$ is higher. Plastic deformation occurs in various directions (suitably oriented grains), thus the difference is not localized in its slip plain.

Based on the results we can conclude that uniaxial tensile test does not provide objective information regarding the plastic properties of material. Hydraulic biaxial tensile test is more suitable for DR tinplate thinner than $0.18 \mathrm{~mm}$, as it provides more objective information on plastic properties of DR tinplate.

\section{REFERENCES}

1. Aerts T., Dimogerontakis Th., DeGraeve I., Fransaer J., Terryn H. (2007), nfluence of the anodizing temperature on the porosity and the mechanical properties of the porous anodic oxide film, Surface and Coatings Technology, 201(16-17), 7310-7317.

2. European Standard EN 10202:2001 (2001) Cold reduced tin mill products-electrolytic tinplate and electrolytic chromium/ $\mathrm{Cr}$ oxide coated steel, The European Standard Publications, Brussels.

3. Gburík R., Černík M., Legatt R., Vranec P. (2015), Crystallographic texture of light tinplate coatings made in various electrolytes, IOP Conference Series: Materials Science and Engineering, 82(1), 4.

4. Hill R. (1952), On discontinuous plastic states with special reference to localized necking in thin sheets, Journal of the Mechanics and Physics of Solids, 1, 19-30.

5. Kvačkaj T., Bacsó J. , Bidulská J. , Lupták M., Pokorný I., Kvačkaj M., Vlado, M. (2010), Influence of cryo and classic rolling conditions on processing parameters of C-Si steel, Acta Metallurgica Slovaca, 16(4), 268-276

6. Kvačkaj T., Bidulská J. (2014), From micro to nano scale structure by plastic deformations, Materials Science Forum, 783-786, 842-847.

7. Makarov P.V., Schmauder S., Cherepanov O.I., Smolin I.Yu., Romanova V.A., Balokhonov R.R., Saraev D.Yu., Soppa E., Kizler P., Fischer G., Hu S., Ludwig M. (2004), Simulation of elasticplastic deformation and fracture of materials at micro-, meso- and macrolevels, Theoretical and Applied Fracture Mechanics, 37(1-3), 183-244.
8. Makarov P.V., Schmauder S., Cherapanov I.O., Smolin Yu.I., Romanova A.V., Balokhonov R.R., Saraev D.Yu., Soppa E., Kizler P., Fischer G., Hu S., Ludwig M. (2001), Simulation of elasticplastic deformation and fracture of materials at micro, meso- and macrolevels, Theoretical and Applied Fracture Mechanics, 37, 183-244.

9. Marciniak Z. (1978), Mechanics of sheet metal forming, Plenum Press, New York.

10. Mihaliková M., Ambriško L., Pešek L. (2011), Videoextensometric measuring of deformation processes in automotive steel sheets at two strain rate levels, Kovové materiály, 49(2), 137-141.

11. Slota J., Spišák E., Jurčišin M. (2014), Local strain hardening and non-uniformity of plastic strain of tinplate, Key Engineering Materials, 606, 23-26.

12. Spišák E., Majerníková J. (2014), The Loss of Plastic Properties Stability of Thin Tinplates and Its Influence on Change of Corrosive Resistance, Applied Mechanics and Materials: Novel Trends in Production Devices and Systems 2, 693, 340-345.

13. Spišák E., Džupon M., Majerníková J., Spišáková Dul'ová E. (2015), Failure of coatings of tinplates, Acta Metallurgica Slovaca, 21(3),213-219

14. Spišák E., Majerníková J. (2014a), The Loss of Plastic Properties Stability of Thin Tinplates and Its Influence on Change of Corrosive Resistance, Applied Mechanics and Materials, 693, 340-345.

15. Spišák E., Slota J., Majerníková J. (2011), The analysis of plastic strain of single and double reduced tinplates, Chem. Lett., 105, 485-487.

16. Spišák E., Slota J., Majerníková J., Kaščák L'., Malega P. (2012), Inhomogeneous plastic deformation of tinplates under uniaxial stress state, Chem. Lett., 106, 537-540.

17. Spišák E., Majerníková J. (2012), Analysis of variance of mechanical properties of sheets as the input parameters for simulation of processes, Acta Metallurgica Slovaca, 18(2-3), 109-116.

18. Spišák E., Majerníková J. (2014b), The Loss of Plasticity Stability, Applied Mechanics and Materials: Novel Trends in Production Devices and Systems 2, 693, 346-351.

19. Swift H.W. (1952), Plastic instability under plane stress, Journal of the Mechanics and Physics of Solids, 1(1), 1-18.

20. Yu H., Burgess I.W., Davison J.B., Plank R.J. (2008), Journal of Constructional Steel Research, 64(5), 515-525.

21. Zhang J., Jiang Y. (2004a), A study of inhomogeneous plastic deformation of 1045 steel, J. Eng. Mater. Technol., 126, 164-172.

22. Zhang J., Jiang Y. (2004b), Lüders bands propagation of 1045 steel under multiaxial stress state, International Journal of Plasticity, 21, 651-670.

23. Zhang J., Jiang Y.A. (2005), International Journal of Plasticity, 21(3), 651-670.

The authors are grateful to APVV for support of experimental work under grant APVV-14-0834 and the project VEGA No. 1/0872/14. 